\title{
Promise of nano revolution hasn't materialized
}

$\mathrm{S}$ ilver nanoparticles, while presumably an effective weapon against very tiny vampires, have long been touted as the technology of the future that would transform medicine.

But more than a decade after former United States president Bill Clinton said that nanotechnology would yield another "industrial revolution," the promise of medical technologies using materials on the order of a billionth of a metre hasn't exactly materialized.

New diagnostic tools using nanowires, or new treatments that slip in and deliver chemotherapy directly into tumors, remain a distant dream. Researchers remain uncertain about how silver nanomaterials will act when reduced to miniscule sizes and it's unclear what adverse effects will result if they are put into the human body.

But they say there may be a more immediate role for silver nanoparticles, as an antibacterial agent in an era of increasing concern about hospitalacquired infections.

Silver nanoparticles are already being embedded into anti-stink socks, washing machines and medical devices such as surgical tools and disinfectant sprays because of their antimicrobial characteristics. But the extent to which that has occurred is unclear and scientists say they are still trying to figure out the best and safest way to use the material.

Among the possibilities is impregnating intravenous catheters with antimicrobial silver nanoparticles, which would mean that they could changed every two to three weeks, instead of every few days, says Dr. Horacio Bach, an adjunct professor in the division of infectious diseases at the University of British Columbia's Department of Medicine and head of a team that is now testing the nanoparticles against macrophages, the body's first immunological line of defense. Preliminary results indicate there is no significant toxic effect to cells so long as the ratio stays under $2 \mu \mathrm{g} / \mathrm{mL}$.

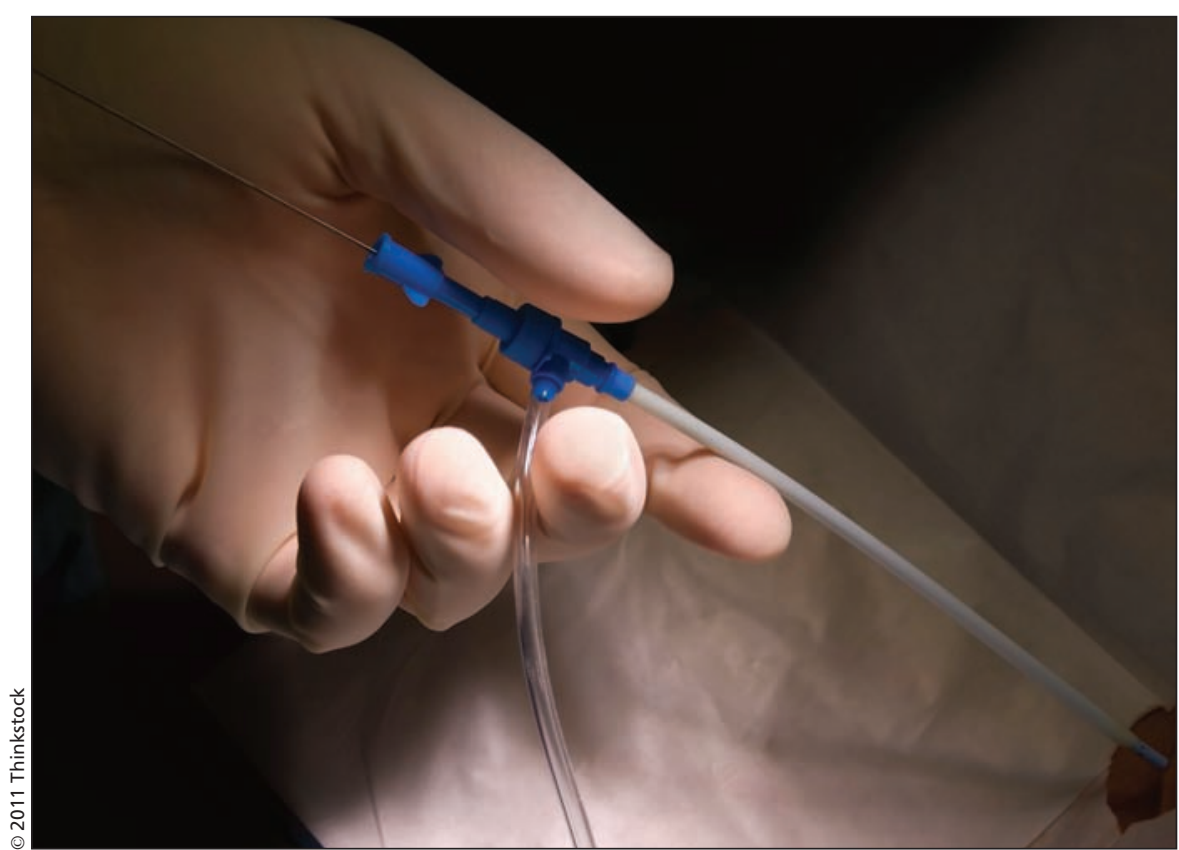

Among the possible uses of antimicrobial silver nanoparticles is impregnating them in intravenous catheters, which would mean they might not need to be changed every few days, but rather, every few weeks.

While the miniscule size of nanoparticles is seductive, that size also makes it difficult to ascertain the consequences of their use in humans. There are virtually no studies done in vivo, so potential chemical interactions or long-term sideeffects are unclear.

A recent paper concluded that blocks of silver, such as earrings, shed nanoparticles as a matter of course, implying that humans have been exposed to silver nanoparticles ever since we started using the metal - and without apparent consequence (ACS Nano 2011;5[11]: 8950-57).

“[The study's results] doesn't mean there isn't a risk, but it means that we may need to recalibrate that risk," says Dr. Andrew Maynard, director of the Risk Science Center at the University of Michigan School of Public Health.

But others aren't convinced that silver nanoparticles are a promising avenue for medicine. They "don't work" in medicine and are a dead end, in terms of medical applications, says Dr. Robert Burrell, professor and chair of biomedical engi- neering at the University of Alberta in Edmonton and Canada Research Chair in nanostructured biomaterials.

"There's an overwhelming amount of material about nanomaterials and how good they are," he adds. "But if you actually critically look at the papers, you can see that people were looking to get an effect, and they designed their experiment to get that effect in many instances."

"These people aren't fibbing. They're showing that you can get an antimicrobial effect in a test-tube.'

Burrell says a more promising approach may lie in the use of nanocrystalline silver, which he used to invent a wound dressing that he says is now being used to treat burn victims in 40 countries.

Beyond research lies the thorny issue of government regulation related to the use of nanotechnologies in medicine.

Both Canada and the United States recently released policy statements on nano safety, with the US National Sci- 
ence and Technology Council Committee on Technology's Subcommittee on Nanoscale Science, Engineering, and Technology proposing a comprehensive framework for nano research that better integrates risk assessment into the development of nanotechnologyenabled products (www.nano.gov/sites /default/files/pub_resource/nni_2011_ehs _research_strategy.pdf). Canada, by contrast, unveiled a "tool to help the
Department gather safety information about nanomaterials" (www.hc-sc.gc .ca/sr-sr/pubs/nano/pol-eng.php).

Health Canada appears disinclined to move with any manner of new regulations. Rather, the department hopes to regulate the use of nanomaterials within existing legislative frameworks such as the Food and Drugs Act, says Laird Roe, the director of policy, planning and coordination at Health Canada. "Internation- ally, everyone's facing the same problem. Things are being done on a case by case basis."

But even if the government were inclined to regulate, it would probably be imprudent and impossible, as there are no hard and fast rules that apply to all materials at the nano level, Maynard says. - Sabrina Doyle, Ottawa, Ont.

CMAJ 2011. DOI:10.1503/cmaj.109-4068 